\title{
PHYSICAL ASPECTS OF REVERSIBLE INACTIVATION OF ENDOTOXIN*
}

\author{
J. A. Rudbach, R. L. Anacker, W. T. Haskins, A. G. Johnson,
}

K. C. Milner, E. Ribi

U.S. Department of Health, Education, and Welfare, Public Health Service, National Institutes of Health,

National Institute of Allergy and Infectious Diseases, Rocky Mountain Laboratory, Hamilton, Mont.;

Department of Microbiology, University of Michigan, Ann Arbor, Mich.

Most early investigations of the chemistry of endotoxins were limited to gross analyses. It soon became apparent that subtler means of degradation, such as enzymes, were necessary to determine structural configurations and intramolecular relationships within the endotoxin complex. Just such a subtle endotoxin-degrading system was suggested by the observation of Hegemann (1954) that human plasma factors inactivated the pyrogenic properties of endotoxin. The applicability of this reaction became particularly evident when further studies showed that smaller-sized antigenic units of endotoxin appeared to be produced during the plasma-endotoxin reaction (Rudbach and Johnson, 1961, 1962; Skarnes and Chedid, 1964). The kinetics of the endotoxin-altering reaction, measured by reduction in the pyrogenicity of endotoxin (Keene, Landy and Shear, 1961) and by reduction in ability of endotoxin to precipitate quantitatively with homologous antiserum (Stauch and Johnson, 1959), lent credence to the theory that a plasma enzyme was degrading the endotoxin polymer. This endotoxin-altering system was shown to be inhibited by divalent cations (Rosen et al., 1958) and by other plasma components (Yoshioka and Johnson, 1962). These and other observations (cf. Atkins, 1960; Landy, 1960) supported the contention that a plasma enzyme was degrading the endotoxin polymer. However, proof of this must be the isolation of degraded products which have come from a previously intact endotoxin molecule. This evidence has not been presented to date. Furthermore, other evidence has indicated that endotoxin may not be cleaved by plasma hydrolases. Rudbach and Johnson (1964) demonstrated that, after alteration of endotoxin by plasma, activity could be restored by procedures not considered likely to reverse an enzymatic hydrolysis.

\section{Method of Alteration and Restoration of Endotoxin Activity}

As shown in FIGURE 1, Salmonella typhosa endotoxin was incubated with fresh human plasma or plasma fraction IV-1. Samples of the unaltered and

*Supported in part by USPHS Grant E1524 (Johnson) and USPHS fellowship 1-F2-AI-23,032-01 from National Institute of Allergy and Infectious Diseases (Rudbach). 


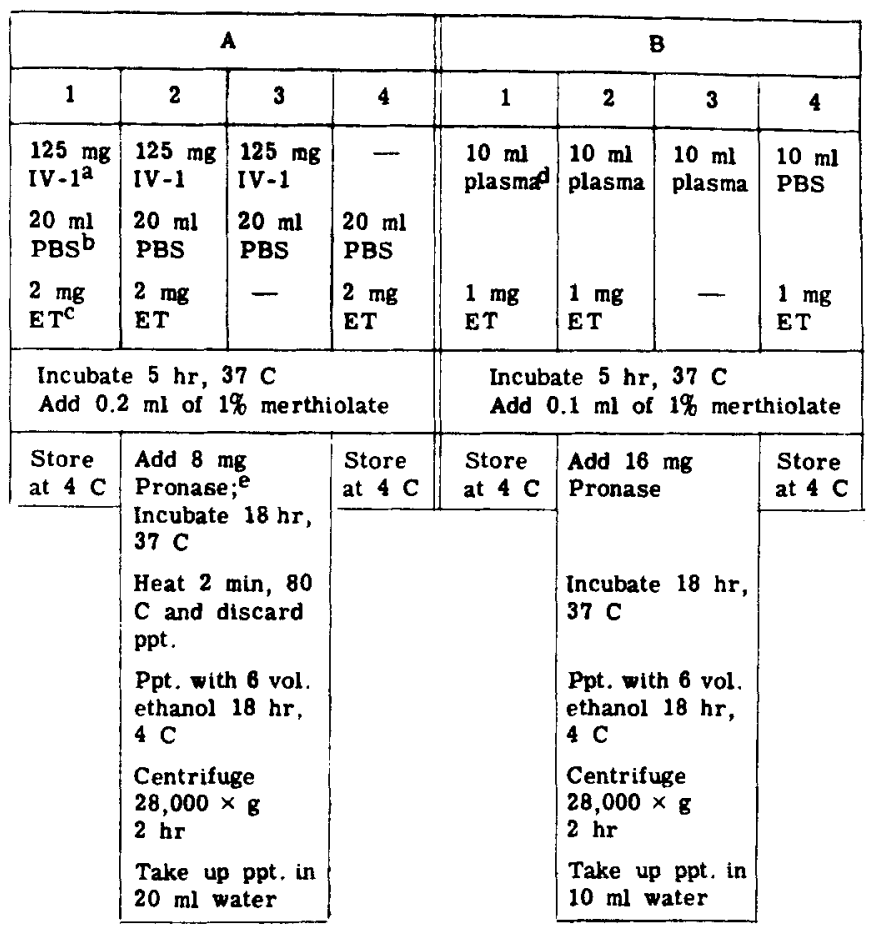

\footnotetext{
aV-1: Human plasma fraction IV-1 (Cohn).

bPBS: Phosphate buffered saline.

CET: $\quad$ Endotoxin (Boivin) extracted from S. typhosa 0-901.

dPlasma: Pooled human plasma collected into ACD solution and used within $3 \mathrm{hr}$.

epronase: A protease from Streptomyces griseus.
}

FIGURE 1. Protocol for alteration and restoration of endotoxin.

altered endotoxin were stored at $4^{\circ} \mathrm{C}$ while another sample of the altered endotoxin and a plasma protein control were digested with a proteolytic enzyme followed by precipitation with ethanol. Note that the ethanol precipitate was taken up in the same volume as the original incubated mixture, so that the concentration of endotoxin should remain unchanged.

\section{Pyrogenicity of the Altered and Restored Endotoxin}

The first to be recognized and probably the most commonly measured alteration of endotoxin produced by incubation with plasma is reduction in pyrogenicity. When samples of endotoxin were incubated with Cohn fraction IV-1 of human plasma or with whole human plasma in the manner outlined in FIGURE 1, the pyrogenicity of the endotoxin was diminished as shown in FIGURES 2 and 3. However, when preparations of altered endotoxin were 


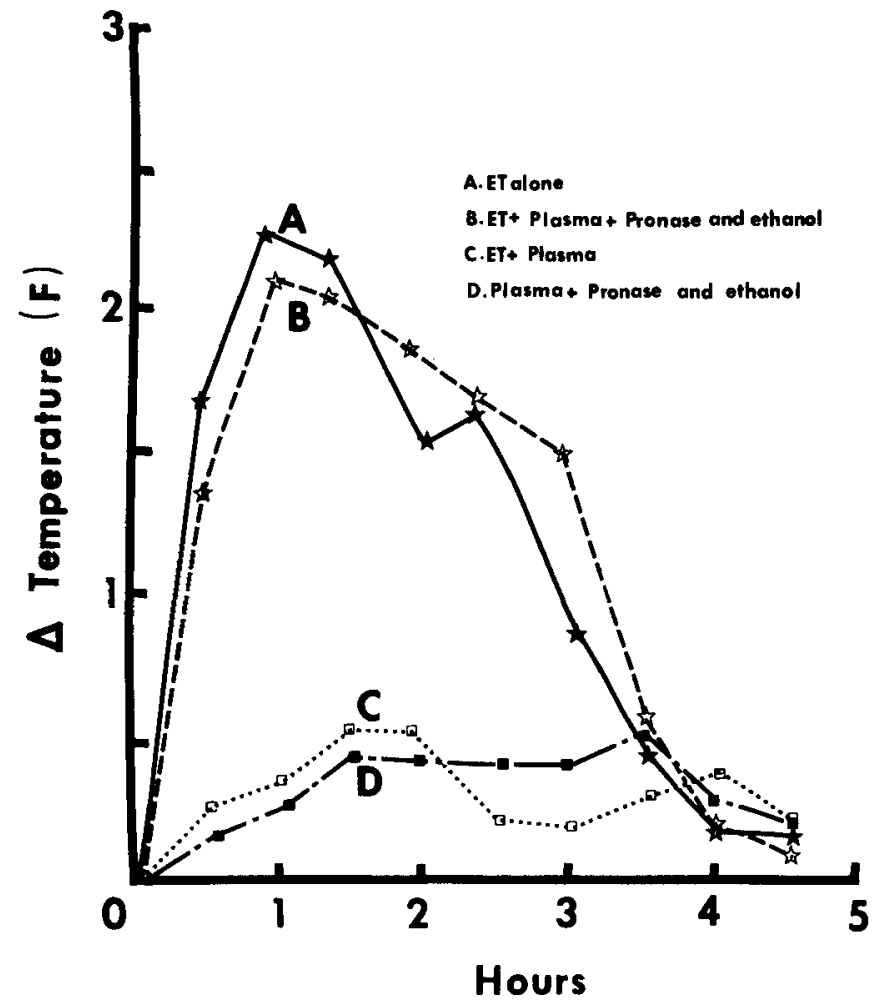

FIGURE 2. Pyrogenic responses of rabbits to endotoxin preparations altered by human plasma and restored by pronase and ethanol treatment. Each curve represents the average temperature response of three rabbits to $0.1 \mu \mathrm{g}$ of the endotoxin or equivalent dilutions of control solutions.

carried through the procedure outlined for restoration of endotoxin activity, the pyrogenicities of endotoxin altered either by fraction IV-1 or by fresh human plasma could be restored. The negative controls of fraction IV-1 and human plasma, carried through the same steps used for restoration of endotoxin, validate these results. Not shown is the control of endotoxin alone carried through the restoration procedure, because its pyrogenicity was not affected by pronase and ethanol.

\section{Immunologic Reactivity of Altered and Restored Endotoxin}

Another criterion of the alteration of endotoxin by human plasma has been reduction in antigenicity - both the ability to stimulate antibody formation (Landy et al., 1959) and the ability to precipitate quantitatively with homologous antiserum (Stauch and Johnson, 1959; Yoshioka and Johnson, 1962). When varying volumes of an endotoxin solution altered by incubation with 


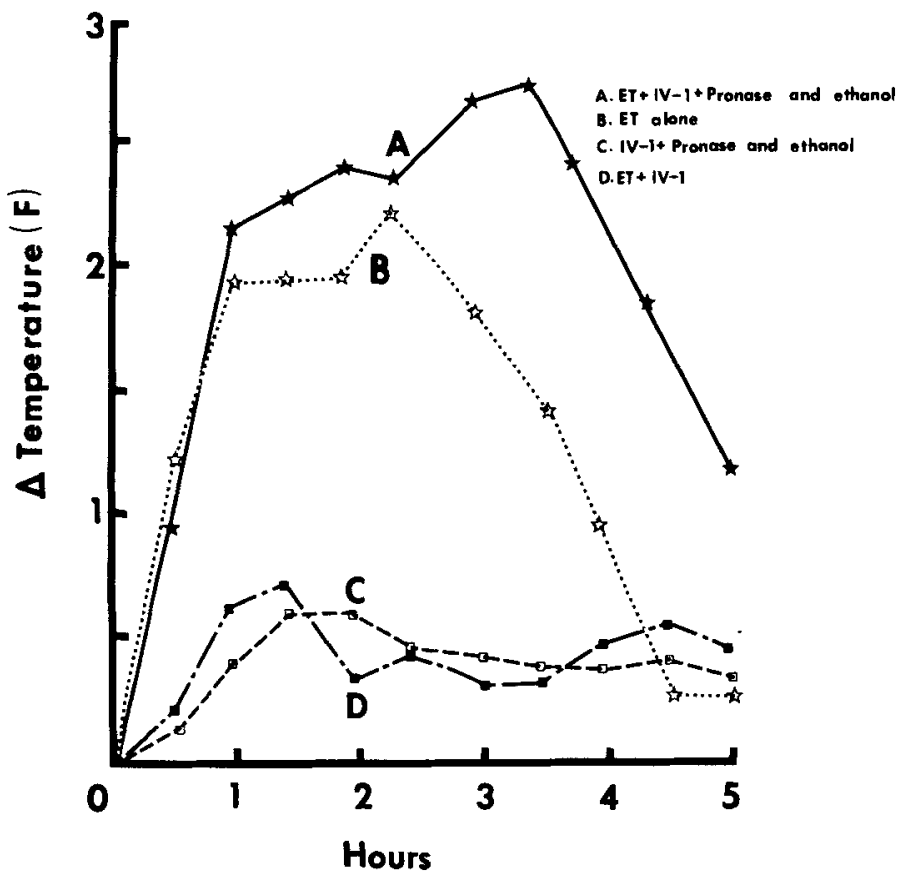

FIGURE 3. Pyrogenic responses of rabbits to endotoxin preparations altered by fraction IV-1 and restored by pronase and ethanol treatment. Fach curve represents the average temperature response of three rabbits to $0.1 \mu \mathrm{g}$ of endotoxin or equivalent dilutions of control solutions.

fraction IV-1 were added to constant volumes of antiserum, the antibody nitrogen precipitated, as quantitated by the micro-Kjeldahl technique, was considerably less than that precipitated by corresponding amounts of endotoxin not so altered (FIGURE 4). Again, treatment of the altered endotoxin with pronase and ethanol restored its ability to precipitate with homologous antiserum in a manner quantitatively and qualitatively similar to that of the endotoxin control.

Endotoxin altered by fresh human plasma also displays a reduced ability to precipitate with antiserum. However, during the restoration of this preparation, some plasma proteins were denatured and interfered with the nitrogen analyses of the quantitative precipitates. Therefore, the endotoxin was externally labeled with hexavalent ${ }^{51} \mathrm{Cr}$ by the method of Braude et al. (1955). This preparation and appropriate controls were altered by fresh human plasma and restored by the pronase and ethanol treatment. The samples were then tested by the usual quantitative precipitation test, except that the precipitates were quantitated by scintillation counting rather than by nitrogen analysis. Restoration of endotoxin which had been altered by incubation in fresh human plasma is shown in FIGURE 5. Incubation of endotoxin in plasma 


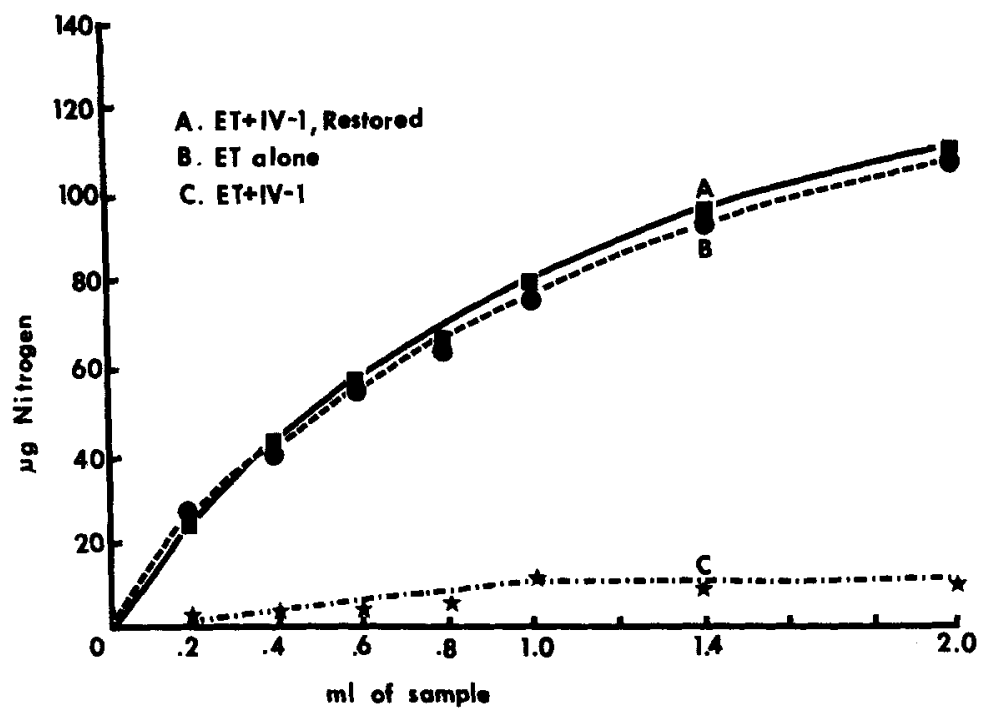

FIGURE 4. The ability to be precipitated by homologous antiserum of: endotoxin altered by fraction IV-1 $(C)$, altered endotoxin treated with pronase and ethanol $(A)$, and endotoxin in saline (B).

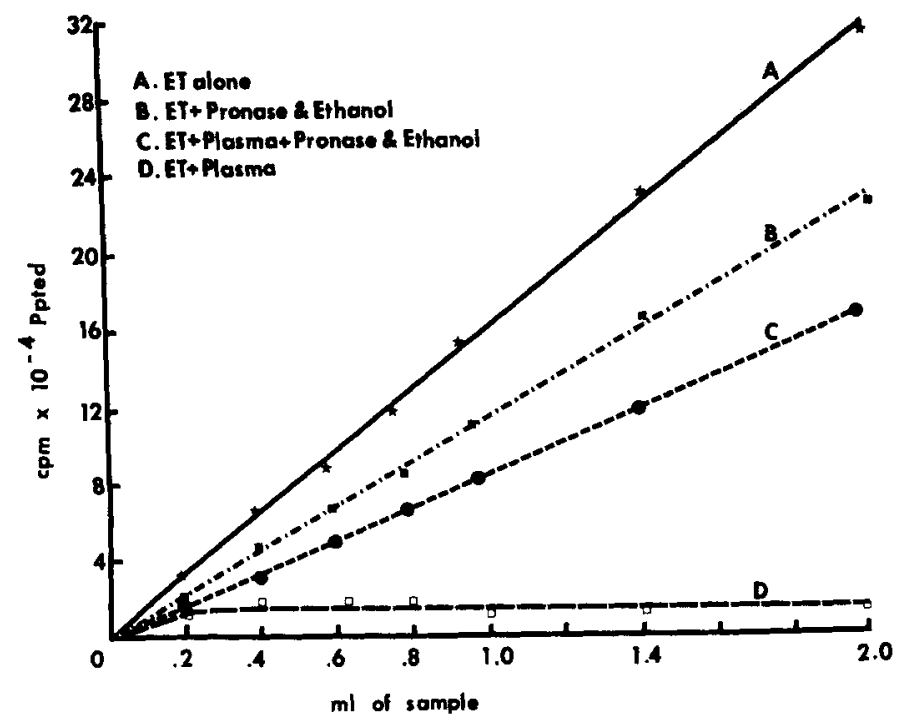

FIGURE 5. The ability to be precipitated by homologous antiserum of: ${ }^{51} \mathrm{Cr}$ endotoxin (A), ${ }^{51} \mathrm{Cr}$ endotoxin altered by human plasma (D), ${ }^{51} \mathrm{Cr}$ endotoxin treated with pronase and ethanol $(\mathrm{B})$, and ${ }^{51} \mathrm{Cr}$ endotoxin altered by human plasma and restored by pronase and ethanol treatment $(\mathrm{C})$. 
resulted in an alteration of the endotoxin so that less than 10 per cent was recoverable by quantitative precipitation. Pronase and ethanol treatment of this altered endotoxin could restore it to 74 per cent of the serological reactivity of the unaltered endotoxin control, which had been treated with pronase and ethanol. It also appears (FIGURE 5) that pronase and ethanol treatment reduced the ability of endotoxin to precipitate with homologous antiserum. This effect was not demonstrable when the precipitates were quantitated by their nitrogen contents. A similar quantitative restoration of radioactive endotoxin which had been altered by fraction IV-1 has been demonstrated (Rudbach and Johnson, to be published).

Cluff (1956) has shown that incubation of Shigella endotoxin with human plasma changed the gel-precipitation pattern of the endotoxin. The several

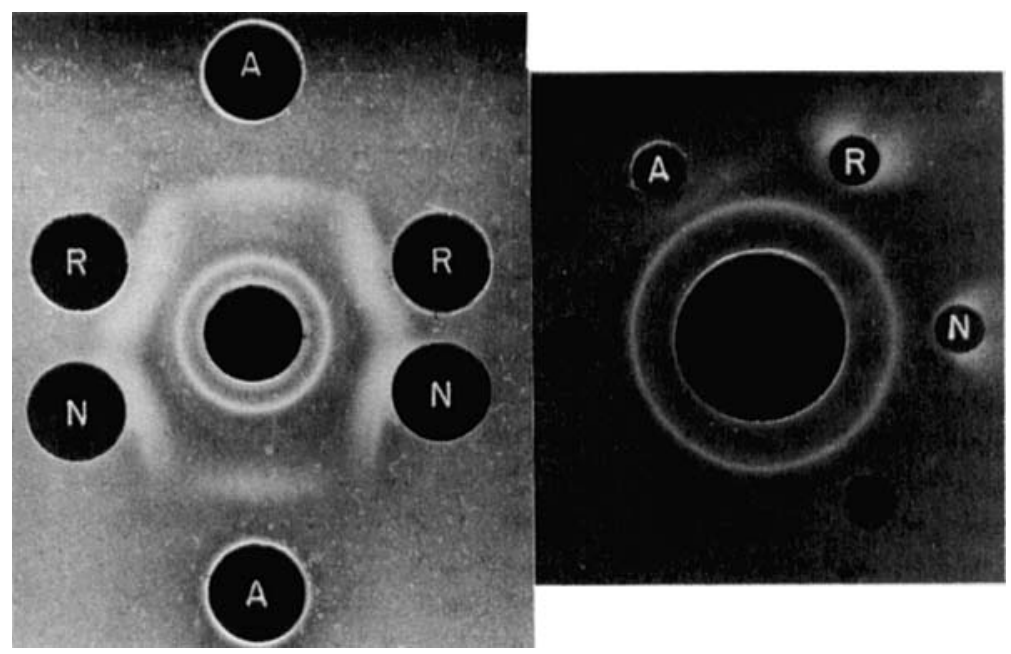

FIGURE 6. Photographs of immunodiffusion plates containing antiendotoxin serum in the center wells, endotoxin altered by fraction IV-1 in the A wells, native endotoxin in the $\mathrm{N}$ wells, and restored endotoxin in the $\mathrm{R}$ wells.

bands of precipitate in the unaltered endotoxin were lost and appeared to be replaced by a single band of precipitate. We showed that similar changes were apparent when $S$. typhosa endotoxin, altered by human plasma proteins, was tested in immunodiffusion plates (Rudbach and Johnson, 1962). Furthermore, this immunodiffusion pattern of altered endotoxin could be restored by pronase and ethanol treatment to a pattern which exhibited marked similarity to the immunodiffusion pattern of unaltered endotoxin. This is shown in FIGURE 6 . Note that the restored endotoxin precipitates with antiserum close to and concave toward the antigen well, similar to and forming a junction of continuity with the precipitation arc of native endotoxin. On the other 
hand, the altered endotoxin forms a straight line of precipitate equidistant between the antigen and antiserum wells. It also forms a junction of continuity with both restored and native endotoxin.

\section{A New Hypothesis of the Mechanism of the Alteration of Endotoxin by Plasma}

Inasmuch as immunodiffusion tests of altered endotoxin suggested a reduction in the particle size and the restoration procedure indicated that a hydrolytic cleavage of the molecule was not probable, a paradox was present, unless the physical changes in the altered endotoxin polymer could be accounted for by a binding with plasma proteins. However, recent studies by Ribi $e$ al. (to be published), following observations by Mora and Young (1961), Oroszlan and Mora (1963), and Oroszlan, Mora and Shear (1963), have suggested a logical explanation of this enigma.

This thesis is formulated as follows: During incubation of endotoxin in plasma, substances with surfactant properties depolymerize the endotoxin macromolecule into smaller elements which are then bound by plasma proteins. The end result is alteration of serological, biological, and physical characteristics of the molecule. With this hypothesis, the observed physical and biological alterations of endotoxin could be explained. In addition, the efficacy of pronase in removing the protein and of ethanol to separate endotoxin from the surfactant, in the restoration procedure, would become apparent. The surfactant used to test this hypothesis was the common bile salt, sodium desoxycholate. However, preliminary studies indicated that sodium cholate may function in an identical manner.

\section{Effect of Varying Amounts of Sodium Desoxycholate ( $\mathrm{NaD}$ ) on Biological and Physical Properties of Endotoxin from Escherichia Coli}

FIGURE 7 shows the febrile responses elicited by phenol-extracted endotoxin from cell walls of $E$. coli in the presence of varying concentrations of $\mathrm{NaD}$. Also shown are the patterns given by the preparations in the ultracentrifuge. As the concentration of $\mathrm{NaD}$ was reduced, the pyrogenicity of the preparations increased and, concurrently, an endotoxic component with a sedimentation coefficient greater than $4 \mathrm{~S}$ appeared. These data are also representative of the behavior of an aqueous ether-extracted endotoxin from Salmonella enteritidis, and a highly purified phenol-water extract of Bordetella pertussis, tested in varying concentrations of $\mathrm{NaD}$. It is interesting that all endotoxins tested, regardless of bacterial origin, or method of extraction, appeared to regain full pyrogenicity when the concentration of $\mathrm{NaD}$ was reduced to 0.062 per cent. 


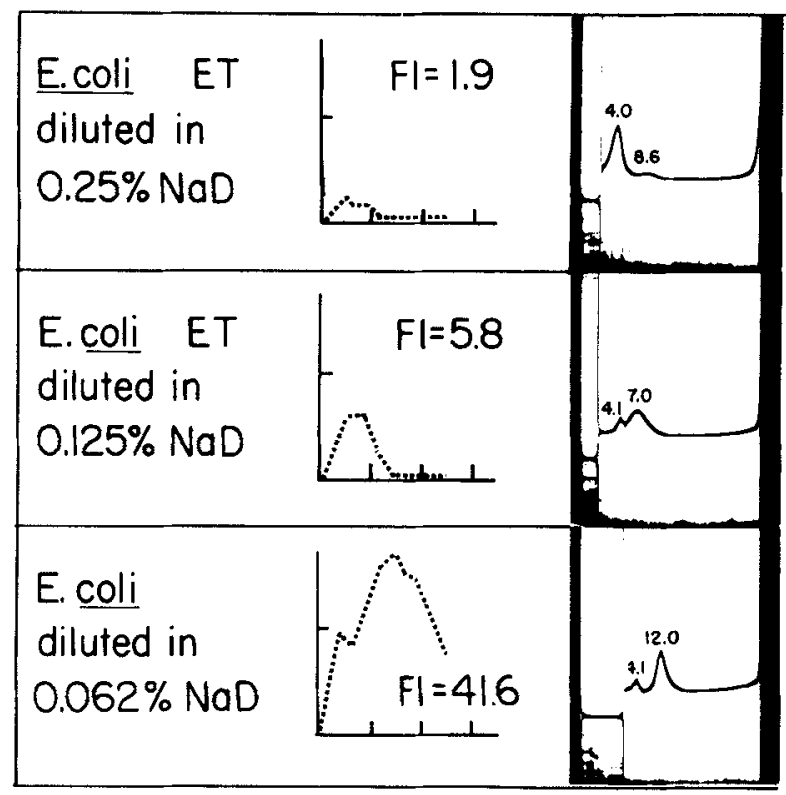

FIGURE 7. Pyrogenic responses, including fever indices (FI), elicited by $0.5 \mu \mathrm{g}$ of Escherichia coli endotoxin in varying amounts of $\mathrm{NaD}$; and ultracentrifuge patterns of the corresponding samples at 0.5 per cent endotoxin concentration.

\section{Effect of Sodium Desoxycholate (NaD) and Human Plasma on the Pyrogenicity of Endotoxin from Salmonella Enteritidis}

In the preceding section, it was shown that endotoxin treated with a sufficient concentration of $\mathrm{NaD}$, and diluted in $\mathrm{NaD}$, for the pyrogenicity determination had lost its ability to elicit a fever in rabbits. However, if NaD-treated endotoxin was diluted in saline it displayed a normal (or a slightly augmented) pyrogenicity, when compared to the endotoxin control. This is demonstrated with an aqueous ether-extracted endotoxin from $S$. enteritidis in FIGURE 8. When human plasma was added to endotoxin in the presence of $\mathrm{NaD}$, the solution did not regain pyrogenicity after dilution in saline. Under the conditions of this test the plasma alone did not reduce the pyrogenicity of the endotoxin. Thus, we hypothesize that a plasma factor(s) was binding to the dissociated endotoxin elements and preventing them from reassociating upon dilution of the bile salt. We would also theorize that, when endotoxin was tested for pyrogenicity after dilution in $\mathrm{NaD}$, the plasma factors were combining with the endotoxin elements in vivo, preventing their reaggregation, and thereby inactivating the pyrogenicity of the preparation. Also shown in FIGURE 8 is the pyrogenic response elicited by the endotoxin- $\mathrm{NaD}$-plasma mixture which has been restored by the pronase and ethanol treatment. 


\begin{tabular}{|c|c|c|c|}
\hline $\begin{array}{l}\text { Endotoxin } \\
\text { alone }\end{array}$ & $F 1=29.6$ & $\begin{array}{l}\text { Endotoxint } \\
0.5 \% \mathrm{NaD} t \\
1 \mathrm{ml} \text { plasma }\end{array}$ & $F I=0$ \\
\hline $\begin{array}{l}\text { Endotoxint } \\
0.5 \% \mathrm{NaD} \\
\text { (diluted in } \\
\text { saline) }\end{array}$ & $F I=$ & $\begin{array}{l}\text { Endotoxint } \\
0.5 \% \text { NaDt } \\
1 \mathrm{ml} \text { plasma } \\
\text { (restored) }\end{array}$ & $\begin{array}{l}7.4 \\
. \\
1\end{array}$ \\
\hline $\begin{array}{l}\text { Endotoxint } \\
1 \mathrm{ml} \text { plasma }\end{array}$ & 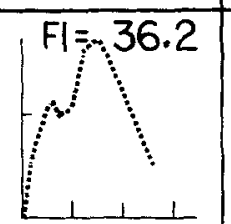 & $\begin{array}{l}\text { Endotoxin + } \\
1 \mathrm{ml} \text { plasma } \\
\text { (restored) }\end{array}$ & $\begin{array}{c}\mathrm{FI}=29.2 \\
1 \\
1\end{array}$ \\
\hline
\end{tabular}

FIGURE 8. Pyrogenic responses, including fever indices (FI), elicited by $0.1 \mu \mathrm{g}$ of Salmonella enteritidis endotoxin preparations, treated with $\mathrm{NaD}$, plasma, or both; and restored.

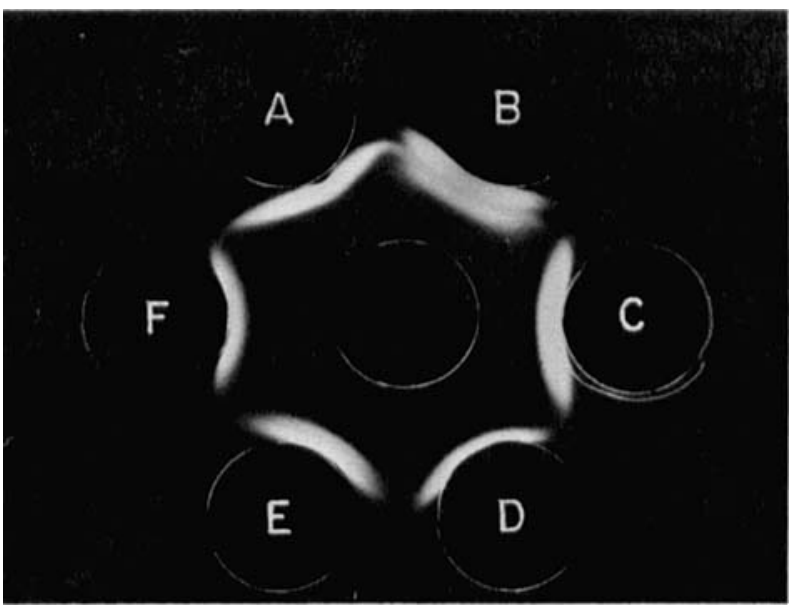

FIGURE 9. Photograph of an immunodiffusion plate containing antiserum to Salmonella enteritidis endotoxin in the center well; endotoxin treated with $\mathrm{NaD}$ in well $\mathrm{A}$; endotoxin treated with $\mathrm{NaD}$ plus human plasma in well $\mathrm{B}$; the endotoxin- $\mathrm{NaD}$-plasma mixture, restored with pronase and ethanol in wells $\mathrm{C}$ and $\mathrm{F}$; unaltered endotoxin and plasma in well $\mathrm{E}$; unaltered endotoxin and plasma, treated with pronase and ethanol in well $D$. 
The endotoxin which had been dissociated with bile salt and treated with human plasma was also tested for its precipitation pattern in two-dimensional immunodiffusion plates (FIGURE 9). Inasmuch as the agar in the immunodiffusion plate contained no $\mathrm{NaD}$, the precipitation pattern of endotoxin treated with $\mathrm{NaD}$ (well $\mathrm{A}$ ) appeared similar to that of endotoxin alone. However, the pattern of endotoxin in $\mathrm{NaD}$ plus plasma (well $\mathrm{B}$ ) was similar to that exhibited by altered endotoxin. Treatment of the endotoxin-NaD-plasma mixure with pronase and ethanol restored the precipitation pattern (wells $\mathrm{C}$ and $\mathrm{F}$ ) to one of unaltered endotoxin. Under the conditions of this test the plasma alone did not alter the immunodiffusion pattern of the endotoxin (well E). The precipitation arc close to well $\mathrm{D}$ is the result of the unaltered endotoxin and plasma mixture which had been treated with pronase and ethanol. These immunodiffusion tests appear to reinforce the similarities apparent between endotoxin altered by human plasma and endotoxin treated with bile salt and a small amount of plasma.

\section{Electron Microscopy of E. Coli and S. Enteritidis Endotoxins Before and After Treatment with NaD}

Many endotoxin preparations will not form clear solutions under physiological conditions. This is probably due to the presence of aggregates of a smaller basic toxic unit, because soluble endotoxins of full toxicity can be prepared (Ribi et al., 1960). When a sufficient concentration of bile salt was added to a turbid endotoxin suspension, immediate clearing was noted. When the surfactant was subsequently removed by dialysis, the endotoxin solution still remained clear, but had regained full toxicity. Electron micrographs of negatively stained preparations of a phenol-water-extracted endotoxin from E. coli and of this same endotoxin after treatment with 2 per cent $\mathrm{NaD}$ and dialysis are shown in FIGURE 10, $\mathrm{A}$ and $\mathrm{B}$. The phenol-extracted endotoxin (A) contains long filamentous particles along with some smaller rod forms. The polydispersity of the preparation is striking. After treatment with and removal of $\mathrm{NaD}(\mathrm{B})$, the endotoxin appears as shorter rods, somewhat more regular in size than the original endotoxin. The appearance of club-shaped molecules possibly results from flattening of the particles upon the supporting membrane. An aqueous ether-extracted endotoxin from $S$. enteritidis, which is quite soluble, appears as a polydisperse mixture of short rods in the electron micrographs (FIGURE 11-A). Following treatment with 0.5 per cent $\mathrm{NaD}$ and then removal of the bile salt, the endotoxin preparation appears to contain a more uniform population of shortened particles (FIGURE 11-B), which are fully toxic and have a particle weight of about 500,000. However, if this $\mathrm{NaD}$-treated endotoxin is extracted with hot phenol-water and recovered from the aqueous phase, the endotoxin units appear to aggregate linearly as shown in FIGURE 11-C. Physical measurements with solution techniques have confirmed the findings observed with electron microscopy. Up to 


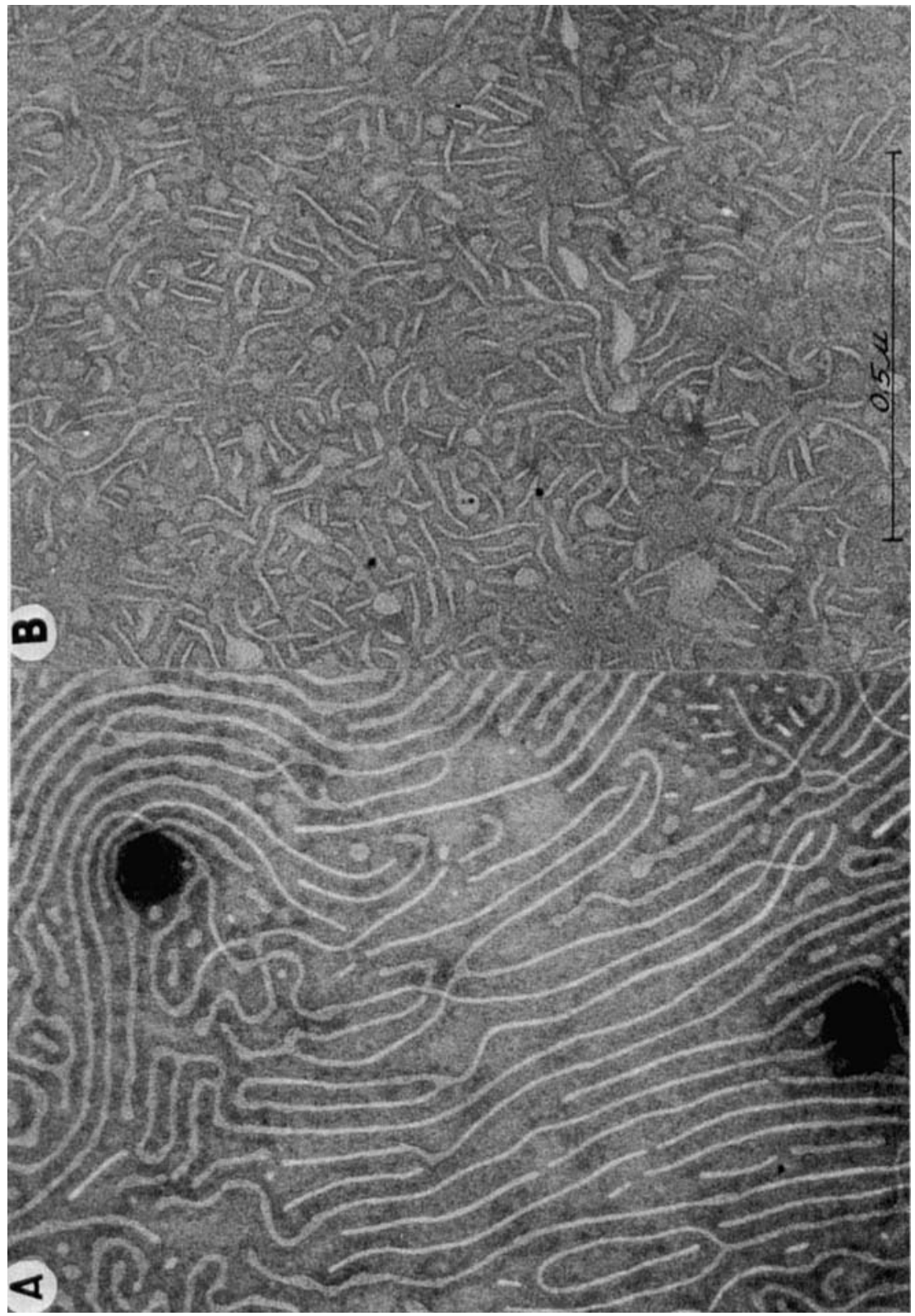

FIGURE 10. Electron micrographs of negatively stained preparations of a phenol-water extracted endotoxin from Escherichia coli: A, normal endotoxin; B, the same preparation after treatment with 2 per cent $\mathrm{NaD}$ and removal of the bile salt by dialysis. 


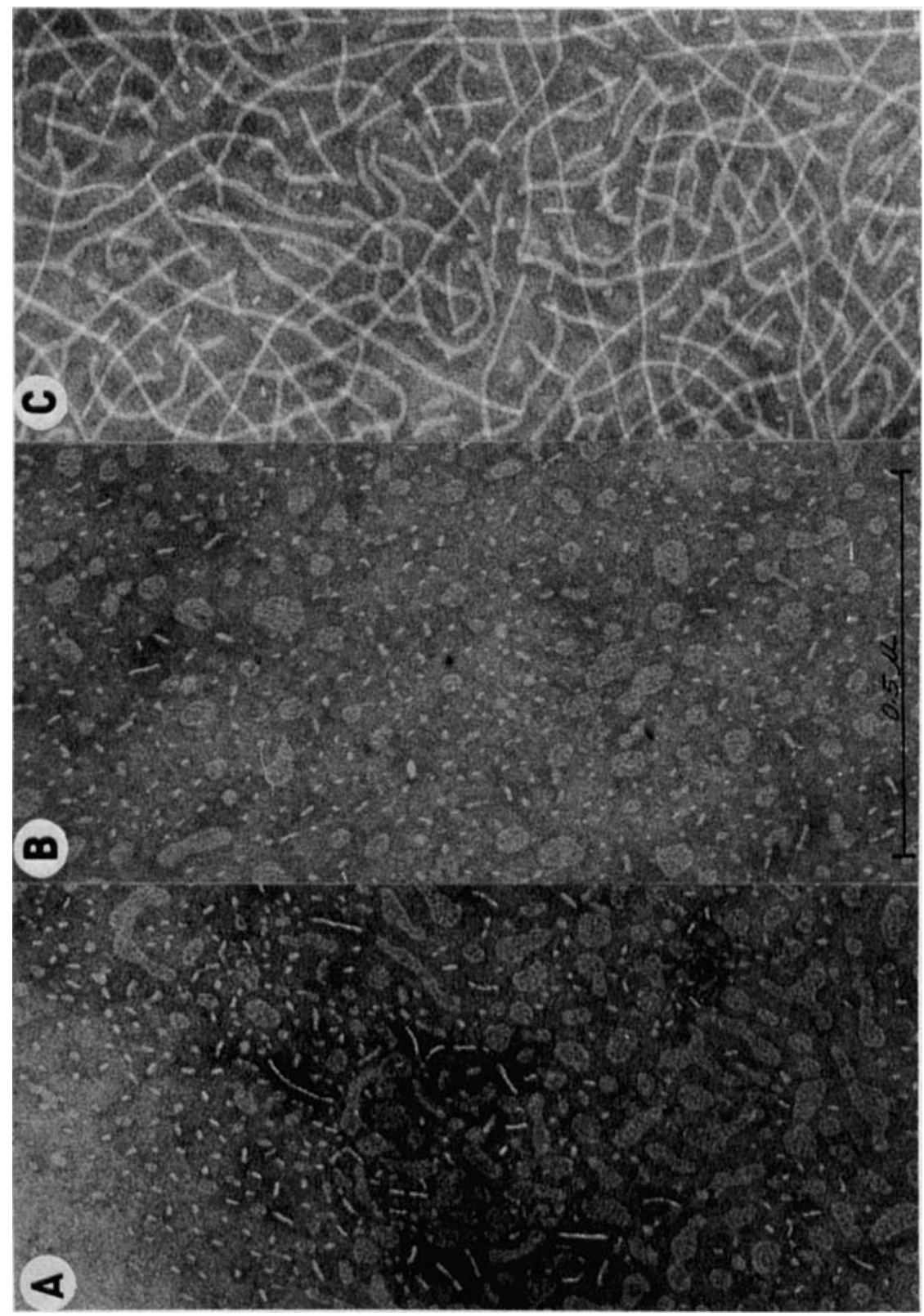

FIGURE 11. Electron micrographs of negatively stained preparations of an aqueousether extracted endotoxin from Salmonella enteritidis: A, the normal endotoxin; B, the endotoxin after treatment with 0.5 per cent $\mathrm{NaD}$ and removal of the bile salt by dialysis; $\mathrm{C}$, preparation B after treatment with phenol. 
now, we have been unable to observe with the electron microscope endotoxin elements in the presence of $\mathrm{NaD}$. However, other physical measurements indicate that the fully dissociated endotoxin may be composed of elements with particle weights of 10,000-80,000 (Ribi et al., to be published). We are presently attempting to isolate those nontoxic elements, which may well be of haptenic nature, in a dissociated state so that full chemical and physical analyses can be performed.

\section{Summary and Conclusions}

On the basis of data presented in this report and elsewhere (Rudbach and Johnson, 1964; Rudbach and Johnson, to be published; Ribi et al., to be published) we have formulated a working hypothesis to explain the mechanism of the reversible inactivation of endotoxin. This hypothesis is outlined schematically in FIGURE 12. An endotoxin prepared by hot phenol-water extraction is, typically, a very long aggregate with average particle weight in the tens of millions. $\mathrm{NaD}$ appears not only to dissociate this polymer by separat-

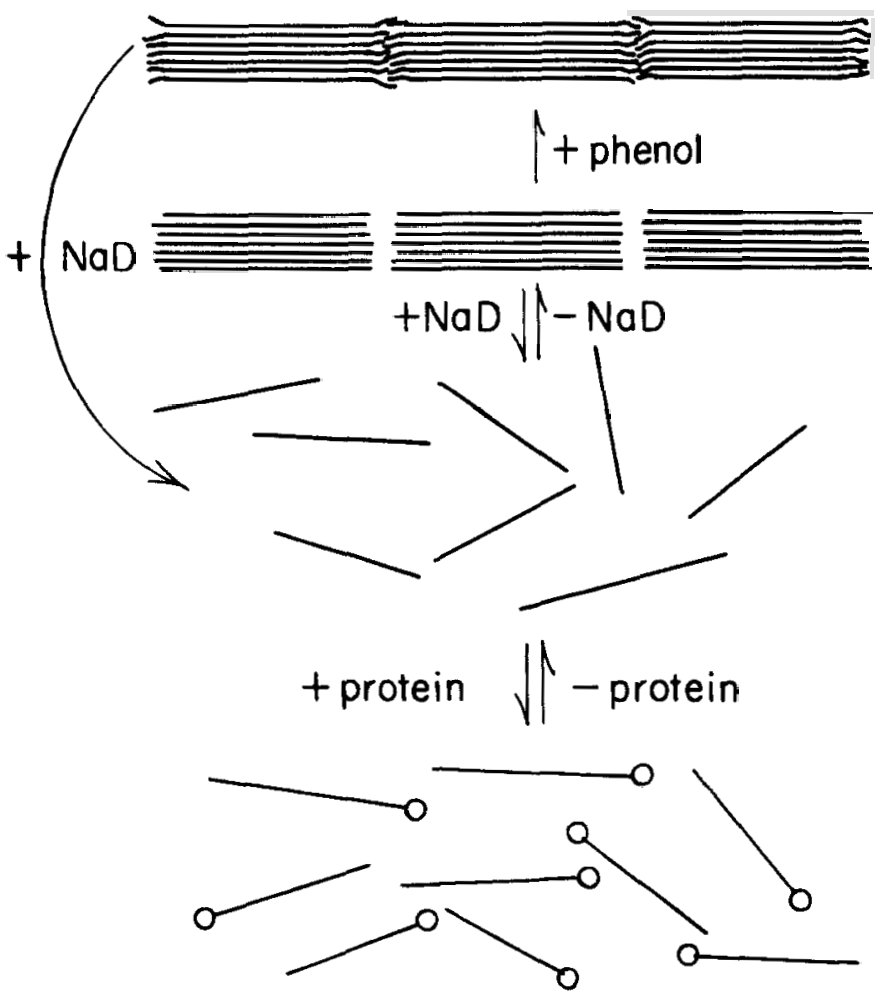

FIGURE 12. Schematic diagram of a working hypothesis to explain the reversible inactivation of endotoxin. 
ing the basic toxic units from one another, but also by splitting these units into smaller nontoxic structural elements. These structural elements reassociate readily if the surfactant is removed by dialysis or dilution. However, certain proteins appear to bind to these elements, preventing their reassociation. All of these reactions are reversible, so that the protein-bound, nontoxic components of endotoxin can be restored to the toxic 500,000 particle-weight form. The latter, however, may not represent the smallest possible toxic form. These units can then be reaggregated by phenol to form the long strings of endotoxin units commonly observed. Endotoxin prepared by aqueous-ether extraction appears to be a polydisperse solution containing one, two or three of the toxic units in short chains. Linear aggregation of the smallest toxic and antigenic units, as suggested previously (Milner et al., 1963), may occur through a linking of fringe micelles as diagrammed in FIGURE 12.

\section{References}

ATKINS, E. 1960. Pathogenesis of fever. Physiol. Rev. 40: 580-646.

BRAUDE, A. I., F. J. CAREY, D. SUTHERLAND \& M. ZALESKY. 1955. Studies with radioactive endotoxin. I. The use of $\mathrm{Cr}^{51}$ to label endotoxin of Escherichia coli. J. Clin. Invest. 34: 850-857.

CLUFF, L. E. 1956. A study of the effect of serum on the immunological reaction of a bacterial endotoxin. J. Exptl. Med. 103: 439-452.

HEGEMANN, F. 1954. Zur Bedeutung des Blutserums für die Entstehung und das Unwirksamwerden bakterieller Reizstoffe beim Menschen. II. Die neutralisierende Wirkung des menschlichen Serums auf das Endotoxin von Colibakterien. Z. Immunitat. 111: 213-225.

KEENE, W. R., M. LANDY \& M. J. SHEAR. 1961. Inactivation of endotoxin by humoral component. VII. Enzymatic degradation of endotoxin by blood plasma. J. Clin. Invest. 40: $302-310$.

LANDY, M. 1960. Inactivation of endotoxin by humoral systems. Ann. N. Y. Acad. Sci. 88: $1273-1277$.

LANDY, M., R.-J. TRAPANI \& M. J. SHEAR. 1959. Inactivation of endotoxin by a humoral component. IV. Alteration in the immunological properties of typhoid endotoxin. J. Exptl. Med. 110: 731-750.

MILNER, K. C., R. L. ANACKER, K. FUKUSHI, W. T. HASKINS, M. LANDY, B. MALMGREN \& E. RIBI. 1963. Symposium on relationship of structure of microorganisms to their immunological properties. III. Structure and biological properties of surface antigens from Gram-negative bacteria. Bacteriol. Rev. 27: 352-368.

MORA, P. T. \& B. G. YOUNG. 1961. Interaction of an endotoxin with cationic macromolecules. J. Gen. Microbiol. 26: 81-95.

OROSZLAN, S. I. \& P. T. MORA. 1963. Dissociation and reconstitution of an endotoxin. Biochem. Biophys. Res. Commun. 12: $345-349$.

OROSZLAN, S. I., P. T. MORA \& M. J. SHEAR. 1963. Reversible inactivation of an endotoxin by intracellular protein. Biochem. Pharmacol. 12: 1131-1146.

RIBI, E., R. L. ANACKER, W. T. HASKINS, B. MALMGREN, K. C. MILNER \& J. A. RUDBACH. To be published.

RIBI, E., B. H. HOYER, K. C. MILNER, T. D. PERRINE, C. L. LARSON \& G. GOODE. 1960. Physical and chemical analysis of endotoxin from Salmonella enteritidis. J. Immunol. 84: $32-47$.

ROSEN, F.S., R. C. SKARNES, M. LANDY \& M. J. SHEAR. 1958. Inactivation of endotoxin by a humoral component. III. Role of divalent cations and a dialyzable component. J. Exptl. Med. 108: 701-711.

RUDBACH, J. A. \& A. G. JOHNSON, 1961. Alteration of bacterial endotoxin by human plasma fraction $\mathrm{IV}_{1}$ (Cohn). Bact. Proc., pg. 131. 
RUDBACH, J. A.\& A. G. JOHNSON. 1962. Changes in serologic reactivity of endotoxin induced by fraction IV $\mathrm{V}_{1}$ (Cohn) of normal human serum. Proc. Soc. Exptl. Biol. Med. 111: 651-655.

RUDBACH, J. A. \& A. G. JOHNSON. 1964. Restoration of endotoxin activity following alteration by plasma. Nature 202: $811-812$.

RUDBACH, J. A. \& A. G. JOHNSON. Alteration of endotoxin activity following complexing with plasma proteins. To be published.

SKARNES, R. C. \& L. C. CHEDID. 1964. Biological degradation and inactivation of endotoxin (chromate-labeled) in Bacterial Endotoxins, eds. M. Landy and W. Braun. Rutgers University Press. 575-587.

STAUCH, J.E. \& A. G. JOHNSON. 1959. The alteration of bacterial endotoxins by human and rabbit serum. J. Immunol. 82: 252-263.

YOSHIOKA, M. \& A. G. JOHNSON. 1962. Characteristics of endotoxin altering fractions derived from normal human serum. J. Immunol. 89: 326-335. 